\title{
Attitudes and current practices of primary care clinicians in performing anal cancer screening
}

\author{
Kelly Scarberry ${ }^{1}$, Bona Ko ${ }^{2}$, Jay J Idrees ${ }^{2}$, Justin T Brady ${ }^{2}$, Emily Steinhagen ${ }^{2}$ and Sharon L Stein ${ }^{2 *}$ \\ ${ }^{1}$ Case Western Reserve University School of Medicine, Cleveland, Ohio, USA \\ ${ }^{2}$ Department of Surgery, Division of Colorectal Surgery, University Hospitals Cleveland Medical Center, Cleveland, OH, USA
}

\begin{abstract}
Current guidelines regarding anal cancer screening are limited. We sought to determine the anal cancer screening practices among physicians in primary care specialties.

In 2017, a survey was conducted among 578 physicians from the primary care specialties of internal medicine (IM), family medicine (FM) and obstetrics and gynecology (ob/gyn) regarding their anal cancer screening practices. The survey questions focused on patient demographics, practice setting, history and physical examination practices, and physician's personal confidence in anal cancer screening.

There were 103 (17.8\%) respondents and 89\% completed the entire survey. Physician specialties were most commonly FM (39\%) or IM (39\%), compared to ob/gyn (22\%). Ob/gyn physicians more frequently took patient sexual histories more than once per year (ob/gyn: 39\% vs FM: 3\%, IM: 5\%; p<0.005) and asked questions regarding receptive anal intercourse practices, anal condylomata, cervical dysplasia or sexually transmitted diseases ( $<<0.005$ ). IM and ob/gyn physicians also more commonly performed anorectal exams once per year (ob/gyn: 64\%, IM: 69\% vs FM: 43\%, p=0.06). Overall, 40\% physicians reported that they referred patients due to lack of training and 15\% referred due to lack of equipment. A large proportion reported lower personal confidence (1 or 2 out of 5 on Likert scale) with their anal cancer screening practices (ob/gyn: 41\%, FM: 50\%, IM: 53\%)
\end{abstract}

There is significant variability among primary care physicians regarding their practices of anal cancer screening. Lack of training and limited guidelines are likely factors contributing towards inadequate anal cancer screening.

\begin{abstract}
Abbreviations: Family Medicine-FM; Human Immunodeficiency Virus-HIV; Human Papillomavirus-HPV; Internal Medicine- IM; Obstetrics and Gynecology-ob/gyn
\end{abstract}

\section{Introduction}

Anal squamous cell carcinoma is a relatively rare malignancy, affecting approximately two per 100,000 people in the United States, but the incidence of anal cancer is rising [1,2]. Anal cancer is analogous to cervical cancer; the human papilloma virus (HPV) has a close association with dysplasia and neoplasia in both cancers. Immunosuppression, including infection with human immunodeficiency virus (HIV), increases the risk of progression from dysplasia to cancer [2-5]. In high-risk populations, including HIV-positive individuals and men who have sex with men, the rate of anal cancer is higher than the rate of cervical cancer in women in the general population [6-8].

Unlike cervical cancer, recommendations and implementation of standard screening guidelines are not well established, despite evidence that 5 year survival rates are improved with early detection $[9,10]$. Most of the data for anal cancer screening relates to surveillance for patients who have developed anal dysplasia and recommendations for monitoring patients for progression [11-13]. Studies demonstrating screening practices for patients who may be at risk are limited. Data highlighting attitudes of physicians treating patients with HIV found that although many were aware of the risks of anal cancer, they did not routinely screen patients $[14,15]$. To our knowledge, there are no published data on screening in general practice patients or highlighting referral patterns for screening.
Currently, there is a knowledge gap regarding the clinical practices for anal cancer screening by primary practitioners. Further understanding of current practices, and obstacles to screening will enable us to better create screening guidelines and focus educational efforts about anal cancer. We sought to determine the existing practices and patterns of anal cancer screening among these providers at a large health care system, where primary care providers frequently serve as the first point of contact for the patients who may be susceptible for anal cancer.

\section{Methods}

Physicians from the University Hospitals Health System in Cleveland, Ohio, USA, were asked to complete an Institutional Review Board-approved internet-based survey via Surveymonkey (SurveyMonkey Inc. San Mateo, California, USA). The University Hospitals Health System is a large health care entity consisting of eighteen hospitals and fifteen ambulatory sites in Northeastern Ohio. Providers work at a variety of health care settings. The survey was sent to family medicine (FM), internal medicine (IM), and obstetrics

${ }^{\star}$ Correspondence to: Sharon Stein, University Hospitals Cleveland Medical Center, Department of Surger 11100 Euclid Ave Cleveland, OH 44106, USA, Tel: (216) 844-2873; E-mail: sharon.stein@uhhospitals.org

Key words: anal cancer, cancer screening, primary care

Received: July 31, 2018; Accepted: August 24, 2018; Published: August 27, 2018 
and gynecology (ob/gyn) providers via email. Completion of the questionnaire was deemed consent for inclusion in the study.

The survey consisted of demographic information including type of practice, years of practice, and practice setting. Providers were asked to characterize their practice regarding patient age ranges, gender, and whether $10 \%$ or more of the provider's patient population were "at risk" population. For the purposes of the study, "at risk" was defined as HIVpositive, transplant recipients, on chronic immunosuppression, or men who have sex with men. Physicians were asked about sexual historytaking practices, anorectal exam practices, anal cancer screening practices, and personal confidence in their ability to screening for anal cancer using a Likert Scale. If physicians did not screen patients for anal cancer, they were asked for the reason they did not screen and whether they referred any patients for screening.

For statistical analysis, all categorical and ordinal variables are presented as frequencies with percentages and were compared using the chi square test or Fisher's exact test, where appropriate. All analysis was performed using Stata SE Version 14.2 (StataCorp, College Station, Texas).

\section{Results}

The survey was sent to 578 physicians and 103 (17.8\%) responded: 40 respondents identified as family medicine physicians, 40 as internal medicine, and 23 as obstetrics-gynecology (Table 1). Ninety-two respondents (89\%) completed the survey in its entirety.

\section{Practice Characteristics}

The majority of physicians had been in practice for greater than 10 years. Family medicine $(97.5 \%)$ and internal medicine physicians (90.0\%) were more likely to work in an ambulatory setting when compared to ob/gyn physicians $(69.6 \%)$ (both, $\mathrm{p}<0.005)$. Most practitioners were located in a suburban setting (71.8\%); $17.5 \%$ practiced in an urban setting and $10.7 \%$ practiced in a rural setting.

\section{Patient Characteristics}

Family medicine physicians were more likely to treat both adult and pediatric populations (FM: 95\%, IM: 7.5\%, ob/gyn: 30.4\%; p<0.001). Only two physicians, both IM, identified having $10 \%$ or greater patients in an "at risk" category, limiting further analysis of this subset.

\section{Screening Patterns}

Sexual history taking differed among physician groups (Table 2). $\mathrm{Ob} / \mathrm{gyn}$ physicians were more likely to take a sexual history at least annually (ob/gyn: 78.2\%, FM: 40\%, IM: 32.5\%; p<0.05). Ob/gyn practitioners stated they always took history of sexually transmitted diseases (100\%), and usually asked about cervical dysplasia (95.7\%) and sexual preference (91.3\%). However, fewer ob/gyn physicians inquired about anal receptive intercourse (34.8\%), anal condyloma (30.4\%) and anal dysplasia (8.7\%). IM practitioners usually asked about sexual preference $(80.0 \%)$ and a history of STD's (67.5\%), but only $40 \%$ asked about history of cervical dysplasia in patients. FM physicians asked about history of STD's (90.0\%), sexual preference (70.0\%) and history of cervical dysplasia (70.0\%), but were unlikely to ask any additional questions.

Eighty-percent or more of all physicians performed anorectal exams as part of a routine exam. A screening exam consisted most frequently of a digital rectal exam (ob/gyn: $85.7 \%$, FM: $64.3 \%$, IM: 79.3\%). An external exam was performed by most ob/gyn physicians, but just over half of the IM and FM providers (ob/gyn: 92.9\%, FM: 53.6\%, IM: 55.2\%). Ob/gyn and FM physicians were more likely to perform cervical pap smears than IM physicians (Ob: 100\%, FM: 92.5\%, IM: 57.5\%). Additional instrumentation such as anoscopy, flexible sigmoidoscopy or high resolution anoscopy was rarely used

Table 1. Demographic Data of Primary Care Survey Respondents. "HIV- Human Immunodeficiency Virus. †MSM- Men who have sex with men

\begin{tabular}{|c|c|c|c|c|}
\hline & $\begin{array}{c}\text { Family Medicine, } \\
\text { n (\%) }\end{array}$ & $\begin{array}{c}\text { Internal Medicine, } \\
\text { n (\%) }\end{array}$ & $\begin{array}{c}\text { Obstetrics \& Gynecology, } \\
\text { n (\%) }\end{array}$ & p-value \\
\hline Respondents, n (\%) & 40 & 40 & 23 & \\
\hline Years in Practice & & & & 0.3 \\
\hline$<5$ & $9(22.5)$ & $6(15)$ & $6(26.1)$ & \\
\hline $5-10$ & $2(5)$ & 0 & $2(8.7)$ & \\
\hline $10+$ & $29(72.5)$ & $34(85)$ & $15(65.2)$ & \\
\hline Practice Population & & & & $<0.001$ \\
\hline Adult only & $2(5)$ & $37(92.5)$ & $16(69.6)$ & \\
\hline Adult and Pediatrics & $38(95)$ & $3(7.5)$ & $7(30.4)$ & \\
\hline Practice Gender & & & & $<0.001$ \\
\hline Female Only & 0 & 0 & $22(95.65)$ & \\
\hline Male and Female & $40(100)$ & $40(100)$ & $1(4.35)$ & \\
\hline Practice Setting & & & & 0.007 \\
\hline Hospital Based & $1(2.5)$ & $4(10)$ & $7(30.4)$ & \\
\hline Nonhospital Based & $39(97.5)$ & $36(90)$ & $13(69.6)$ & \\
\hline Setting & & & & 0.005 \\
\hline Rural & $10(25)$ & 0 & $1(4.5)$ & \\
\hline Suburban & $25(62.5)$ & $31(77.5)$ & $18(78.3)$ & \\
\hline Urban & $5(12.5)$ & $9(22.5)$ & $4(17.4)$ & \\
\hline $\begin{array}{l}\text { Is } 10 \% \text { or More of Patient } \\
\text { Population: }\end{array}$ & & & & N/A \\
\hline $\mathrm{HIV}^{*}{ }^{*}$ & 0 & 0 & 0 & \\
\hline Transplant Recipients & 0 & 0 & 0 & \\
\hline Chronic Immunosuppresion & 0 & $2(5)$ & 0 & \\
\hline $\operatorname{MSM} \dagger$ & 0 & 0 & 0 & \\
\hline None of the above & $40(100)$ & $38(95)$ & $23(100)$ & \\
\hline
\end{tabular}


Table 2. Sexual History Practices of Primary Care Survey Respondents. "STDs- Sexually transmitted diseases

\begin{tabular}{|c|c|c|c|c|}
\hline & Family medicine, n (\%) & Internal Medicine, n (\%) & Obstetrics \& Gynecology, n (\%) & p-value \\
\hline $\begin{array}{l}\text { How often do you take a sexual } \\
\text { history? }\end{array}$ & $\mathbf{N}=\mathbf{4 0}$ & $\mathbf{N}=\mathbf{4 0}$ & $\mathbf{N}=\mathbf{2 3}$ & $<0.05$ \\
\hline At initial appointment, only & $8(20)$ & $12(30)$ & $3(13.0)$ & \\
\hline $\begin{array}{l}\text { When a patient has clinically } \\
\text { relevant problem only }\end{array}$ & $16(40)$ & $15(37.5)$ & $2(8.7)$ & \\
\hline Annually & $15(37.5)$ & $11(27.5)$ & $9(39.1)$ & \\
\hline More than once a year & $1(2.5)$ & $2(5)$ & $9(39.1)$ & \\
\hline $\begin{array}{l}\text { Which of the following are part of } \\
\text { your sexual history? } \\
\text { (Select all that apply) }\end{array}$ & $\mathrm{N}=\mathbf{4 0}$ & $\mathbf{N}=\mathbf{4 0}$ & $\mathbf{N}=\mathbf{2 3}$ & \\
\hline Sexual preference & $28(70)$ & $32(80)$ & $21(91.3)$ & 0.1 \\
\hline History of STDs* ${ }^{*}$ & $36(90)$ & $27(67.5)$ & $23(100)$ & $<0.05$ \\
\hline $\begin{array}{l}\text { History of anal receptive } \\
\text { intercourse }\end{array}$ & $5(12.5)$ & $3(7.5)$ & $8(34.8)$ & $<0.05$ \\
\hline History of cervical dysplasia & $28(70)$ & $16(40)$ & $22(95.7)$ & $<0.05$ \\
\hline History of anal condyloma & $3(7.5)$ & $3(7.5)$ & $7(30.4)$ & $<0.05$ \\
\hline History of anal dysplasia & $1(2.5)$ & 0 & $2(8.7)$ & 0.1 \\
\hline $\begin{array}{l}\text { Do you perform cervical pap } \\
\text { smears? }\end{array}$ & $\mathbf{N}=\mathbf{4 0}$ & $\mathbf{N}=\mathbf{4 0}$ & $\mathbf{N}=\mathbf{2 3}$ & $<0.05$ \\
\hline Yes & $37(92.5)$ & $23(57.5)$ & $23(100)$ & \\
\hline No & $3(7.5)$ & $17(42.5)$ & $0(0)$ & \\
\hline
\end{tabular}

by any provider. Frequency of anorectal exam was varied. IM and ob/gyn physicians performed anorectal exams annually compared to a one-time exam for FM physicians, although the difference was not statistically different $(\mathrm{p}=0.06)$ (Table 3$)$.

Half of FM physicians, $52.8 \%$ of IM physicians, and $40.9 \%$ of ob/ gyn physicians reported a poor confidence level (score of 1 or 2 on Likert scale) to perform anal cancer screening. A higher percentage of ob/gyn physicians reported their confidence level as a four or five out of five $(36.0 \%)$ compared to the FM (11.8\%) and IM physicians $(22.3 \%)(\mathrm{p}<0.05),($ Table 4$)$. When asked why they rated themselves as having low confidence, most FM and IM providers stated that they had inadequate training (FM: $45.5 \%$, IM: $30.6 \%$ ) or the patient population did not warrant screening (FM: 30.3\%, IM: 27.8\%), while ob/gyn predominantly stated that they had inadequate training (45.5\%).

Despite poor confidence for screening, most providers did not refer all patients for screening (Table 5). Sixty-eight percent of FM physicians performed screening on patients they felt were at high risk for anal cancer compared with $44.8 \%$ of IM physicians and $35.7 \%$ of ob/gyn physicians $(\mathrm{p}<0.05)$. Less than a third of providers referred patients who were thought to be at high risk for anal cancer (FM: 29.4\%, IM: $16.7 \%$, and ob/gyn: $27.3 \%)$. Numbers increased considerably if the patient had an anorectal finding (FM: 76.5\%, IM: 63.9\%, ob/gyn: 72.7\%). When asked which findings would warrant a screening referral, almost all providers would refer for an anal mass, or anal bleeding (FM: $94.1 \%$, IM: $91.7 \%$, Ob/gyn: 95.5\%), but a fewer physicians would refer for anal condyloma (FM: 70.6, IM: 75, ob/gyn: 68.2\%). If referrals were to be made, the physicians most commonly referred to colorectal surgeons (66\%), followed by gastroenterologists (54\%), and general surgeons (29\%).

\section{Discussion}

With the increasing prevalence of anal cancer risk factors and increasing incidence of anal cancer, the health care system needs to establish guidelines for screening for anal cancer. To date, there is minimal evidence regarding methods of screening for anal cancer. This study helps to elucidate the practice patterns of anal cancer screening among first line providers.
Most of our providers are not comfortable screening for anal cancer. Almost half of the providers surveyed reported confidence levels of 1 or 2 on a 5-point Likert scale. This is not surprising given the lack of information on screening available in the literature. Unlike cervical cancer, for which a robust educational program has significantly increased screening patterns, parallel recommendations for anal cancer have been lacking. After the introduction of the Pap smear in 1928 and colposcopy in the 1970's, the rates of cervical cancer were decreased in half due to aggressive screening and treatment programs [16,17].

There is a wide variety of screening practices elucidated in the study, including both whom should be screened and how they should be screened. More providers did a digital rectal exam than external visual exam. This is surprising as a visual perianal exam, in addition to digital rectal exam, is recommended for anyone with a perianal complaint [18]. Providers rarely used a scope to better visualize changes in the anal mucosa. It was also interesting to note that providers were more likely to refer patients for rectal bleeding rather than for condyloma. The majority of anal condyloma cases are caused by low-risk serotypes of HPV [19,20]. However, these lesions are risk factors for anal cancer and visual changes that accompany anal condyloma infection may represent pre-cancerous lesions [20,21]. It has been suggested that anal condyloma above the dentate line, in MSM, or in HIV-positive individuals warrants consideration of biopsy [22].

The current study is unique because unlike most previous reports that focused on anal cancer screening patterns among specialists, the physician cohort of our study represents the first-line encounter for patients who could possibly require screening for anal cancer. It is difficult to set expectations for primary care providers when we lack standards and algorithms for screening for anal cancer. In lieu of official guidelines, many articles provide recommendations given the lack of resounding evidence for the use of anal cancer screening practices. Nearly all of these recommendations are for high-risk patients, rather than the general patient population. Some advocate for yearly digital anorectal exams in high-risk groups, while others for anal cytology followed by high resolution anoscopy (HRA) if findings are noted, and others recommend HRA alone be used to screen for high-grade squamous intraepithelial lesions and anal cancer [23-25]. 
Table 3. Anal Cancer Screening Methods and Anorectal Examination Practices of Primary Care Survey Respondents. "Out of respondents reporting that they perform anorectal exams

\begin{tabular}{|c|c|c|c|c|}
\hline & $\begin{array}{c}\text { Family medicine, } \\
\text { n (\%) }\end{array}$ & Internal Medicine, n (\%) & Obstetrics \& Gynecology, n (\%) & p-value \\
\hline Do you perform anorectal exams? & $\mathrm{N}=\mathbf{4 0}$ & $\mathbf{N}=\mathbf{4 0}$ & $\mathbf{N}=\mathbf{2 3}$ & 0.3 \\
\hline Yes & $33(82.5)$ & $32(80)$ & $23(100)$ & \\
\hline No & $7(17.5)$ & $8(20)$ & $0(0)$ & \\
\hline $\begin{array}{l}\text { How often do you perform } \\
\text { anorectal exams?* }\end{array}$ & $\mathbf{N}=\mathbf{2 8}$ & $\mathrm{N}=\mathbf{2 9}$ & $\mathrm{N}=14$ & 0.06 \\
\hline Once & $16(57.1)$ & $9(31.0)$ & $4(28.6)$ & \\
\hline Once a year & $12(42.9)$ & $20(69.0)$ & $9(64.3)$ & \\
\hline More than once a year & 0 & 0 & $1(7.1)$ & \\
\hline $\begin{array}{l}\text { Which of the following are } \\
\text { components of your anal/rectal } \\
\text { exam for anal cancer?* }\end{array}$ & $\mathbf{N}=\mathbf{2 8}$ & $\mathrm{N}=\mathbf{2 9}$ & $\mathrm{N}=14$ & \\
\hline External exam & $15(53.6)$ & $16(55.2)$ & $13(92.9)$ & $<0.05$ \\
\hline Digital exam & $18(64.3)$ & $23(79.3)$ & $12(85.7)$ & 0.3 \\
\hline Anoscopy & $2(7.1)$ & $1(3.5)$ & 0 & 0.6 \\
\hline High resolution anoscopy & 0 & 0 & 0 & NA \\
\hline Anal pap smear & $1(3.6)$ & 0 & 0 & 0.6 \\
\hline $\begin{array}{l}\text { Flexible sigmoidoscopy/ } \\
\text { colonoscopy }\end{array}$ & $1(3.6)$ & $5(17.2)$ & $1(7.1)$ & 0.3 \\
\hline $\begin{array}{l}\text { I do not perform anal exams for } \\
\text { cancer screening }\end{array}$ & $11(39.3)$ & $5(17.2)$ & $2(14.3)$ & 0.1 \\
\hline Which patients do you screen? & & & & $<0.05$ \\
\hline All patients & $3(10.7)$ & $15(51.7)$ & $6(42.9)$ & \\
\hline $\begin{array}{l}\text { Only patients I feel are at high } \\
\text { risk for anal cancer }\end{array}$ & $19(67.9)$ & $13(44.8)$ & $5(35.7)$ & \\
\hline $\begin{array}{l}\text { Only patients with a history of } \\
\text { anal dysplasia }\end{array}$ & $6(21.4)$ & $1(3.5)$ & $3(21.4)$ & \\
\hline
\end{tabular}

Table 4. Physician Confidence Levels

\begin{tabular}{|l|c|c|c|c|}
\hline $\begin{array}{l}\text { How confident do you } \\
\text { feel screening patients } \\
\text { for anal cancer? }\end{array}$ & 1 (least confident) & 2 & 3 & 5 (most confident) \\
\hline Family medicine & $10(29.4)$ & $7(20.6)$ & $13(38.2)$ & $4(11.8)$ \\
\hline Internal Medicine & $4(11.1)$ & $15(41.7)$ & $9(25)$ & $6(16.7)$ \\
\hline Obstetrics \& Gynecology & $7(31.8)$ & $2(9.1)$ & $5(22.7)$ & $5(22.7)$ \\
\hline
\end{tabular}

Table 5. Referral Patterns of Primary Care Survey Respondents

\begin{tabular}{|c|c|c|c|c|}
\hline & $\begin{array}{l}\text { Family medicine, } \\
\text { n (\%) }\end{array}$ & Internal Medicine, $\mathrm{n}(\%)$ & Obstetrics \& Gynecology, n (\%) & p-value \\
\hline $\begin{array}{l}\text { When do you refer a patient for anal cancer } \\
\text { screening? }\end{array}$ & $\mathbf{N}=\mathbf{3 4}$ & $\mathbf{N}=36$ & $\mathbf{N}=\mathbf{2 2}$ & \\
\hline I refer all my patients & 0 & $3(8.3)$ & $1(4.5)$ & 0.3 \\
\hline $\begin{array}{l}\text { I refer only patients I feel are at high risk for } \\
\text { anal cancer }\end{array}$ & $10(29.4)$ & $6(16.7)$ & $6(27.3)$ & 0.4 \\
\hline I refer patients with anal dysplasia & $4(11.8)$ & $5(13.9)$ & $8(36.4)$ & $<0.05$ \\
\hline I refer patients with an anorectal finding & $26(76.5)$ & $23(63.9)$ & $16(72.7)$ & 0.5 \\
\hline I refer patients if they have a concerning finding & $25(73.5)$ & $25(69.4)$ & $18(81.8)$ & 0.6 \\
\hline $\begin{array}{l}\text { Not applicable - I treat patients for anal cancer } \\
\text { and do not refer }\end{array}$ & 0 & 0 & 0 & NA \\
\hline Which symptoms do you refer a patient for? & $\mathbf{N}=\mathbf{3 4}$ & $\mathrm{N}=\mathbf{3 6}$ & $\mathbf{N}=\mathbf{2 2}$ & \\
\hline Anal pain & $27(79.4)$ & $29(80.6)$ & $20(90.9)$ & 0.6 \\
\hline Anal bleeding & $32(94.1)$ & $33(91.7)$ & $21(95.5)$ & 1.0 \\
\hline Anal mass & $34(100)$ & $35(97.2)$ & $22(100)$ & 1.0 \\
\hline Condyloma & $24(70.6)$ & $27(75)$ & $15(68.2)$ & 0.8 \\
\hline Hemorrhoids & $15(44.1)$ & $20(55.6)$ & $15(68.2)$ & 0.2 \\
\hline Perianal irritation or rash & $9(26.5)$ & $12(33.3)$ & $6(27.3)$ & 0.8 \\
\hline What are your reasons for not screening? & $\mathbf{N}=\mathbf{3 3}$ & $\mathrm{N}=36$ & $\mathbf{N}=\mathbf{2 2}$ & \\
\hline My patients don't warrant screening & $10(30.3)$ & $10(27.8)$ & $4(18.2)$ & 0.6 \\
\hline Inadequate training & $15(45.5)$ & $11(30.6)$ & $10(45.5)$ & 0.4 \\
\hline I don't have necessary equipment & $6(18.2)$ & $4(11.1)$ & $4(18.2)$ & 0.7 \\
\hline I prefer to send to other providers & $6(18.2)$ & $7(19.4)$ & $2(9.1)$ & 0.6 \\
\hline I screen my own patients & $8(24.2)$ & $15(41.7)$ & $10(45.5)$ & 0.2 \\
\hline
\end{tabular}


Findings from the present study should be interpreted in the context of limitations. As with many surveys, there is potential bias in who chose to participate in the study. Our study was sent through official University Hospitals email, but many providers may not open or read the email, and we did not have the ability to determine if the email was opened or read. In addition, there may be inherent bias in practitioners who complete the email secondary to increased interest in the topic. The low response rate makes generalization from the study difficult, but it does provide us with a limited view of the scope of practice, education, and gaps in our literature. Our survey was created for this study alone and did not undergo extensive validation or testing procedures.

This study demonstrates a need for better screening recommendations, education, and guidelines. The rate of anal cancer is increasing, perhaps in part to more people living with immunosuppression long enough to develop a cancer. But unlike other cancers which are amenable to screening, screening parameters have not yet been developed for anal cancer. It is conceivable that with active screening, the incidence of anal cancer could be dramatically reduced, or even eradicated.

\section{Conclusion}

There is great variability among physicians practicing in primary care specialties regarding their practices in the screening for anal cancer. Variability exists in many aspects of screening including historytaking, physical exam procedures, and referral practices. Primary care providers may benefit from evidence-based guidelines, widespread education, and increased training in order to identify pre-cancerous and early-stage cancer lesions in order to improve patient outcomes.

\section{Conflicts of interest}

The authors declare they have no competing interests.

\section{Funding}

None.

\section{References}

1. Siegel RL, Miller KD, Jemal A (2016) Cancer statistics. CA Cancer J Clin 66: 7-30.

2. Joseph DA, Miller JW, Wu X, Chen VW, Morris CR, et al. (2008) Understanding the burden of human papillomavirus-associated anal cancers in the US. Cancer 113: 2892-2900. [Crossref]

3. Silverberg MJ, Lau B, Justice AC, Engels E, Gill MJ, et al. (2012) Risk of anal cancer in HIV-infected and HIV-uninfected individuals in North America. Clin Infect Dis 54 1026-1034. [Crossref]

4. Moscicki AB, Darragh TM, Berry-Lawhorn JM, Roberts JM, Khan MJ, et al. (2015) Screening for Anal Cancer in Women. J Low Genit Tract Dis 19: S27-S42. [Crossref]

5. Salit IE (2015) Screening for Anal Cancer. Cancer Cytopathol 123: 631-632. [Crossref]
6. Palefsky JM (2006) Human papillomavirus and anal intraepithelial neoplasia. Curr Opin Infect Dis 19: 62-66.

7. Clark MA, Hartley A, Geh JI (2004) Cancer of the anal canal. Lancet Oncol 5: 149157. [Crossref]

8. Frisch M, Glimelius B, van den Brule AJ, Wohlfahrt J, Meijer CJ, et al. (1997) Sexually transmitted infection as a cause of anal cancer. NEngl J Med 337: 1350-1358. [Crossref]

9. Palefsky JM (2015) Screening to prevent anal cancer: Current thinking and future directions. Cancer Cytopathol 123: 509-510.

10. Johnson LG, Madeleine MM, Newcomer LM, Schwartz SM, Daling JR (2004) Anal cancer incidence and survival: The Surveillance, Epidemiology, and End Results experience, 1973-2000. Cancer 101: 281-288.

11. Goldstone SE, Johnstone AA, Moshier EL (2014) Long-term outcome of ablation of anal high-grade squamous intraepithelial lesions: recurrence and incidence of cancer. Dis Colon Rectum 57: 316-323. [Crossref]

12. Pineda CE, Berry JM, Jay N (2007) High resolution anoscopy in the planned staged treatment of anal squamous intraepithelial lesions in HIV-negative patients. $J$ Gastrointest Surg 11: 1410-1416.

13. Dalla Pria A, Alfa-Wali M, Fox P, Holmes P, Weir J, et al. (2014) High-resolution anoscopy screening of HIV-positive MSM: longitudinal results from a pilot study. AIDS 28: 861-867. [Crossref]

14. Ong J, Chen M, Temple-Smith M (2013) The inside story. Physicians' views on digita ano-rectal examination for anal cancer screening of HIV positive men who have sex with men. J Med Screen 20: 188-191.

15. Ong JJ, Temple-Smith M, Chen M, Walker S, et al. (2015) Why are we not screening for anal cancer routinely - HIV physicians' perspectives on anal cancer and its screening in HIV-positive men who have sex with men: a qualitative study. BMC Public Health 15: 67. [Crossref]

16. https://www.hhs.gov/opa/reproductive-health/fact-sheets/cancers/cervical-cancer/ index.html

17. Dexeus S, Cararach M, Dexeus D (2002) The role of colposcopy in modern gynecology Eur J Gynaecol Oncol 23: 269-277. [Crossref]

18. Wietfeldt ED, Thiele J (2009) Malignancies of the anal margin and perianal skin. Clin Colon Rectal Surg 22: 127-135. [Crossref]

19. zur Hausen H (1991) Human papillomaviruses in the pathogenesis of anogenital cancer. Virology 184: 9-13. [Crossref]

20. Shiffman MH (1992) Recent progress in defining the epidemiology of human papillomavirus infection and cervical neoplasia. J Natl Cancer Inst 84: 394.

21. Sobhani I, Walker F, Roudot-Thoraval F, Abramowitz L, Johanet H, et al. (2004) Anal carcinoma: incidence and effect of cumulative infections. AIDS 18: 1561-1569. [Crossref]

22. Metcalf AM, Dean T (1995) Risk of dysplasia in anal condyloma. Surgery 118: 724 726. [Crossref]

23. Lam JM, Hoch JS, Tinmouth J, Sano M, Raboud J, et al. (2011) Cost-effectivenes of screening for anal precancers in HIV-positive men. AIDS 25: 635-642. [Crossref]

24. Darragh TM, Colgan TJ, Cox JT (2012) The Lower Anogenital Squamous Terminology Standardization Project for HPV-Associated Lesions: Background and Consensus Recommendations from the College of American Pathologists and the American Society for Colposcopy and Cervical Pathology. Arch Pathol Lab Med 136: 1266-1297.

25. Machalek DA, Grulich AE, Hillman RJ, Jin F, Templeton DJ, et al. (2013) The Study of the Prevention of Anal Cancer (SPANC): design and methods of a three-year prospective cohort study. BMC Public Health 13: 946. [Crossref]

Copyright: (C2018 Scarberry K. This is an open-access article distributed under the terms of the Creative Commons Attribution License, which permits unrestricted use, distribution, and reproduction in any medium, provided the original author and source are credited. 